\title{
EL SÍNDROME DEL ACOSO INSTITUCIONAL
}

\section{INSTITUTIONAL HARASSMENT SÍNDROME}

\section{AUTORES}

José Luis González de Rivera y Revuelta: Catedrático de Psiquiatría y director del Instituto de Psicoterapia e Investigación Psicosomática de Madrid.

jose.luis@mixmail.com

\section{CURRÍCULUM VITAE}

Doctor en medicina, catedrático de psiquiatría director del titulo propio de la Universidad Autónoma de Madrid (España). “diploma de formación superior en psicoterapia".

\section{RESUMEN}

Un reciente término, el de acoso grupal o mobbing, está empezando a generar, en la práctica clínica, un síndrome de características muy definidas. Los candidatos o individuos de riesgo presentan cuadros clínicos que, de no ser abordados a tiempo, pueden derivar en complicaciones severas.

\section{PALABRAS CLAVE}

Síndrome - Acoso - Institución 


\section{ABSTRACT}

A recent term, the group of harassment or bullying, is beginning to generate, in clinical practice, a syndrome distinct features. Candidates or individuals have clinical risk that, if not addressed early, can lead to severe complications.

\section{KEY WORDS}

Syndrome - Harassment - Institution

Un reciente término, el de acoso grupal o mobbing, está empezando a generar, en la práctica clínica, un síndrome de características muy definidas. Los candidatos o individuos de riesgo presentan cuadros clínicos que, de no ser abordados a tiempo, pueden derivar en complicaciones severas.

REl concepto de acoso grupal o mobbing fue introducido en las ciencias sociales por el etólogo Konrad Lorenz, como extrapolación de sus observaciones en diversas especies de animales en libertad. En su significado original más simple, se llama mobbing al ataque de una coalición de miembros débiles de una misma especie contra un individuo más fuerte. Actualmente, se aplica a situaciones grupales en las que un sujeto es sometido a persecución, agravio o presión psicológica por uno o varios miembros del grupo al que pertenece, con la complicidad o aquiescencia del resto. En realidad, el fenómeno, aunque escasamente estudiado, es conocido desde antiguo como síndrome del chivo expiatorio y síndrome del rechazo de cuerpo extraño. 
Shuster (1996) considera que el acoso institucional es una de las experiencias más devastadoras que puede sufrir un ser humano en situaciones sociales ordinarias. Lo define como "ser objeto de agresión por los miembros del propio grupo social", y lo distingue de dos situaciones próximas: el rechazo social, en el que el individuo puede ser excluido por sus iguales de contactos e interacciones, pero no perseguido, y la desatención social, en la que el individuo es, simplemente, ignorado.

Su ocurrencia se ha descrito en instituciones altamente reglamentadas y homogéneas, como en escuelas, fuerzas armadas y cárceles, así como en instituciones conservadoras, en las que hay poca tolerancia a la diversidad y fuertes vínculos e identidades compartidas entre sus miembros. La presentación de acoso psicológico es más probable en organizaciones relativamente cerradas, cuya cultura interna considera el poder y el control como valores prioritarios sobre la productividad y la eficacia. Por eso, dentro del ámbito laboral, parece darse con más frecuencia en universidades, hospitales y ONG, aunque ninguna entidad, pública o privada, parece estar a salvo del problema.

En cuanto a los individuos con riesgo, varios estudios independientes, como los de Leyman, Schuster y Adams, coinciden en describir en ellos características comunes, que pueden resumirse en las dos siguientes: son diferentes, en aspecto, conducta, valores y actitudes, con respecto al grupo general. Además, su mera presencia provoca un cuestionamiento implícito sobre los símbolos, características y valores que dan homogeneidad al grupo.

Grupos presionados

Aplicando estos dos criterios, podemos clasificar a los sujetos con riesgo de padecer mobbing en tres grandes grupos: los envidiables, personas brillantes y atractivas, 
pero consideradas como peligrosas o competitivas por los líderes implícitos del grupo, que se sienten cuestionados por su mera presencia; los vulnerables, individuos con alguna peculiaridad o defecto, o, simplemente, depresivos necesitados de afecto y aprobación, que dan la impresión de ser inofensivos e indefensos; por último, los amenazantes, activos, eficaces y trabajadores, que ponen en evidencia lo establecido y pretenden imponer reformas o implantar una nueva cultura.

El cuadro clínico reviste dos formas principales: la depresiva y la de estrés-ansiedad. En su vertiente patoplástica depresiva, la clínica es muy parecida a la del síndrome de desgaste profesional o burn-out, aunque con mayores dudas sobre la autoidentidad, y con tendencia a la idealización de las mismas estructuras o personas responsables de la persecución. Recordemos que el síndrome de estrés profesional o burn-out se caracteriza por sensación de estar desbordado, con agotamiento de la capacidad adaptativa. Los síntomas principales del burnout se agrupan en tres categorías: cansancio emocional, que se traduce por agotamiento físico y psíquico, abatimiento, sentimientos de impotencia y desesperanza, desarrollo de un autoconcepto negativo y actitudes negativas hacia el trabajo y la vida en general; evitación y aislamiento, traducido en su conducta a través de absentismo laboral, ausencia de reuniones, resistencia a enfrentarse con personas o atender al público, o en su actitud emocional, que se vuelve fría, distante y despectiva; y sentimiento complejo de inadecuación personal y profesional, con deterioro progresivo de su capacidad laboral y pérdida de todo sentimiento de gratificación personal en el trabajo. Este tercer elemento suele presentarse de manera directa, aunque puede manifestarse también de forma paradójica, encubriéndose con una actitud aparente de entusiasmo e hiperdedicación.

Clínica y repercusión familiar 
La segunda presentación clínica, la de estrés-ansiedad, reviste características comunes con el trastorno de estrés postraumático, con intrusiones obsesivas y sueños repetitivos relacionados con la situación de acoso, hiperactividad simpática, irritabilidad y desarrollo progresivo de conductas de evitación. La repercusión familiar del síndrome puede ser importante, con aumento de la tensión entre los cónyuges y mayor morbilidad general tanto en ellos como en sus hijos. Desde el punto de vista laboral, se acompaña con frecuencia de absentismo, bajas prolongadas y cambios bruscos de entorno laboral.

El suicidio es una complicación grave, sobre la que han llamado recientemente la atención López García Silva y Camps del Saz. El riesgo es particularmente severo en profesionales cualificados que derivan importante gratificación de su trabajo. Leyman señala que la elección del lugar de trabajo como escena del acto suicida se puede interpretar como un último intento de rebeldía o como una acusación póstuma.

Una de las más llamativas características del síndrome, en todas sus formas, es la dificultad de la víctima para entender lo que está pasando y organizar conceptualmente su propia defensa. En términos vulgares, diríamos que "no se lo puede creer". Este factor cognitivo es uno de los mayores obstáculos para la identificación, tratamiento y prevención de este síndrome. De hecho, la mayoría de estudios sobre estrés profesional lo obvian completamente, y ponen todo el énfasis en el propio sujeto más que en la corrección de los condicionantes patógenos del entorno.

Desde el punto de vista psicosocial, dos elementos más son necesarios para completar las circunstancias en las que se desarrolla el síndrome. En primer término, la presencia de una persona que asuma el papel de perseguidor principal, investida de la suficiente autoridad o carisma como para movilizar las dinámicas grupales de 
acoso. Su personalidad presenta una peculiar combinación de rasgos narcisistas y paranoides, que le permiten autoconvencerse de la razón y justicia de su actividad destructiva.

Irigoyen considera que se trata de una forma asexual de perversión, Field la clasifica como una modalidad de sociopatía agresiva, y González de Rivera la describe como "mediocridad inoperante activa", un trastorno de la personalidad caracterizado por exacerbación de tendencias repetitivas e imitativas, apropiación de los signos externos de la creatividad y el mérito, ansia de notoriedad que puede llegar hasta la impostura, y, sobre todo, intensa envidia hacia la excelencia ajena, que procura destruir por todos los medios a su alcance.

Las maniobras principales que el mediocre inoperante activo utiliza para el acoso psicológico de su víctima son las siguientes:

a) Someterle a acusaciones o insinuaciones malévolas, sin permitirle defenderse o expresarse.

b) Aislarle de sus compañeros, privarle de información; interrumpir o bloquear sus líneas de comunicación.

c) Desconsiderar e invalidar su trabajo, distorsionar o tergiversar sus actividades y comentarios, atribuirle motivaciones espúreas o vergonzantes.

d) Desacreditar su rendimiento, dificultar el ejercicio de sus funciones, ocultar sus logros y éxitos, exagerar y difundir, fuera de contexto, todos sus fallos, tanto reales como aparentes. 
e) Comprometer su salud, física y psíquica, mediante una constante presión estresante que favorece las alteraciones depresivas, psicosomáticas, y actos de huida que pueden llegar hasta la renuncia brusca al puesto laboral o al suicidio.

El segundo aspecto se relaciona con la colaboración y permisividad del resto del personal de la organización. La persecución psicológica se desarrolla en medio de un sorprendente silencio e inhibición de los observadores, que, aunque conscientes del abuso e injusticia de la situación, se abstienen de intervenir, sea por complicidad implícita con el plan de eliminación del acosado, sea para evitar convertirse ellos mismos en objeto de represalia. No es del todo infrecuente que individuos ambiciosos de escasa valía profesional aprovechen conscientemente la situación, que les favorece al entorpecer o eliminar a un competidor más cualificado.

Sistemas de salud

Tim Field, que ha estudiado extensamente el mobbing (que él llama bullying) en Inglaterra, considera que los médicos y enfermeras del sistema británico de salud (NHS) corren grave riesgo de sufrir acoso institucional, que, por otra parte, es frecuente en los sistemas de salud en general. Partiendo de la clasificación de los seres humanos, en cuanto a su actitud de servicio, en empáticos y controladores, Field establece el siguiente razonamiento explicativo:

Los rasgos empáticos de personalidad, tales como sensibilidad, comprensión del sufrimiento ajeno e interés por el desarrollo y bienestar de los demás, predominan entre los médicos asistenciales, ya que, entre otras razones, son un determinante natural de su elección profesional. Los controladores predominan entre los burócratas y personal directivo, ya que estos rasgos llevan naturalmente a evitar la relación con el enfermo, y a dedicarse a la gestión, control y optimización de recursos. 
En estas condiciones, la relación de gestión, control y optimización puede fácilmente pervertirse hacia conductas de acoso, por cuanto los burócratas directivos cosifican la relación médico-enfermo, y pueden interpretar algunas actividades empáticas de los médicos asistenciales como un reto o amenaza contra su poder institucional.

http://www.diariomedico.com/psiquiatria/n180700.html 